\title{
REVIEW
}

\section{Vocally disruptive behavior in the elderly: a systematic review}

\author{
Armin von Gunten, ${ }^{1,5}$ Abdel-Messieh Alnawaqil, ${ }^{1}$ \\ Christoph Abderhalden, 2,5 Ian Needham 3,5 \\ and Brigitte Schupbach ${ }^{4,5}$ \\ ${ }^{1}$ Service Universitaire de Psychiatrie de l'Age Avancé (SUPAA), Prilly, Switzerland \\ ${ }^{2}$ Universitäre Psychiatrische Dienste, Bern, Switzerland \\ ${ }^{3}$ Ian Needham, Hochschule für Angewandte Wissenschaften, St. Gallen, Switzerland \\ ${ }^{4}$ Brigitte Schüpbach, Universitätsklinik für Psychiatrie, Bern, Switzerland \\ ${ }^{5}$ Research Group of the Swiss Society for Old Age Psychiatry
}

\section{ABSTRACT}

Background: Vocally disruptive behavior (VDB) in the elderly is a common condition, especially in people with dementia, but difficult to treat. It may occur in as many as $40 \%$ of nursing home residents. This study is a review of the existing literature on this condition.

Method: The literature review was conducted using PubMed (particularly Medline and the Cochrane database) and reference lists from relevant publications in English, French, and German.

Results: Most studies are small and no conclusive prevalence data are available. Many biological and psychosocial treatments have been advocated, but most studies are little more than anecdotal case reports. It is evident that VDB can have deleterious consequences on others and the patients themselves, although no studies specifically examine the range or the pervasiveness of VDB. Etiopathogenic research on VDB is still in its infancy.

Conclusions: Most aspects surrounding VDB are insufficiently understood. The heterogeneity and multiple contributive factors regarding VDB suggest quite convincingly that a panoply of different interventions tailored to the individual's needs will be required to overcome VDB and the suffering related to it.

Key words: behavioral and psychological symptoms of dementia, agitation, elderly, dementia, treatment

\footnotetext{
Correspondence should be addressed to: Armin von Gunten, Service Universitaire de Psychiatrie de l'Age Avancé (SUPAA), Département de Psychiatrie - CHUV, Rte du Mont, 1008 Prilly VD, Switzerland. Phone: +41 2164362 67; Fax: +41 2164362 38. Email: armin.von-gunten@chuv.ch. Received 19 Jul 2007; revision requested 1 Oct 2007; revised version received 22 Nov 2007; accepted 22 Nov 2007. First published online 13 February 2008.
} 


\section{Introduction}

Disruptive behaviors are frequent in the elderly, but according to our clinical experience and a preliminary literature search we have found vocally disruptive behavior (VDB) to be both particularly disturbing and under-researched. Until the early 1990s only a few papers on VDB had been published (Teri et al., 1992). Although an increasing number of studies have since focused on disruptive behaviors in the elderly, they often cover a variety of behaviors rather than focusing on VDB. We therefore decided to conduct a more thorough literature review using a series of key words entered in PubMed, in particular Medline and the Cochrane database, which comprised the words "vocally disruptive behavior OR vocally disruptive behavior OR [disruptive AND vocal*] OR verbal agitation OR screaming, OR muttering OR yelling OR shrieking OR noise-mak*]." The selection criteria were: subjects to be aged 65 years or older, publication date between 1980 and 2006, articles to have abstracts, and articles to be written in English, French or German. In addition, we searched articles according to the snowball system.

\section{Typology of VDB}

Changes in behavior are part of all dementia syndromes and dozens of disturbed behaviors have been described. However, the descriptions of these behaviors are both variable and overlapping so that their definitions are debatable (Nagaratnam et al., 2001a). VDB is not a homogeneous behavior. Alois Alzheimer's patient had VDB as she screamed loudly (Alzheimer, 1907), but other descriptions have since been added and include, besides screaming, shouting, yelling, howling, talking constantly, permanent requests for attention and help, repeating phrases or words, repetitive verbalizations, repetitious noises, groaning, singing loudly, nonsense talking, verbal aggression, making threats implying harm to others or self, abusive or accusatory or hostile or obscene or profane language, complaining, and cursing. These behaviors may all be considered as VDB (Cariaga et al., 1991; Beck et al., 1998; Draper et al., 2000). Further variants of VDB are continuous chattering, muttering, singing or humming, grunting, and bizarre noise-making that can be observed in people with severe dementia (Nagaratnam et al., 2003b).

Classifications based on possible etiological and teleological factors have been suggested such as (1) noise-making which appears purposeless and persistent, (2) noise-making as a response to the environment, (3) noise-making directed towards eliciting a response from the environment, (4) "chatterbox" noisemaking, (5) noise-making in the context of deafness, and (6) other noise-making (Ryan et al., 1988). Thus, VDB can be goal-directed or purposeless (White et al., 1996).

The intensity of VDB can vary considerably both in length or amplitude and can be occasional or nearly constant. In one study, severe VDB vocalizations lasted at least two hours a day (Sloane et al., 1999), and in another study, patients were verbally disruptive during $13 \%$ to $59 \%$ of the observation periods (Hussian 
Table 1. Typology of VDB

\begin{tabular}{|c|c|c|c|}
\hline \multicolumn{2}{|c|}{ Q U A L I T Y } & \multirow[b]{2}{*}{ C A U S E S } & \multirow[b]{2}{*}{ CONSEQUENCES } \\
\hline T Y P E & I NTENS ITY & & \\
\hline $\begin{array}{l}\text { Shouting, screaming, } \\
\text { yelling, howling, } \\
\text { groaning, grunting, } \\
\text { bizarre noises, } \\
\text { repetitive noise } \\
\text { Talking constantly, } \\
\text { rambling, nonsense } \\
\text { talking, permenant } \\
\text { requests, repeating } \\
\text { phrases/words, } \\
\text { echolalia, repetitive } \\
\text { verbalisations, } \\
\text { continuous chattering, } \\
\text { muttering, complaining } \\
\text { Singing loudly, humming } \\
\text { Verbal aggression, threats } \\
\text { implying harm to self } \\
\text { or others, abusive } \\
\text { language, cursing, } \\
\text { accusatory or hostile } \\
\text { language, obscene or } \\
\text { profane or foul } \\
\text { language } \\
\text { Isolated or in association } \\
\text { with other disruptive } \\
\text { behaviours }\end{array}$ & $\begin{array}{l}\text { Acoustic properties } \\
\text { - loudness } \\
\text { - timbre } \\
\text { - shrillness } \\
\text { - others } \\
\text { Repetitiveness } \\
\text { Temporal pattern }\end{array}$ & $\begin{array}{l}\text { Etiology (causal, } \\
\text { precipitating, risk } \\
\text { factors, protective } \\
\text { factors) } \\
\text { - diagnosis (dementia } \\
\text { vs no dementia; } \\
\text { affective and anxiety } \\
\text { disorders, psychosis, } \\
\text { pain, etc.) } \\
\text { - dementia stage } \\
\text { - communication skills } \\
\text { - others } \\
\text { Teleology } \\
\text { Intentionality } \\
\text { Directedness }\end{array}$ & $\begin{array}{l}\text { Disruptiveness on } \\
\text { - other patients } \\
\text { - informal caregivers } \\
\text { - formal caregivers }\end{array}$ \\
\hline
\end{tabular}

and Hill, 1980). Loudness is another disturbing factor with most patients (95\%) being audible at least 50 feet (15 meters) away (Sloane et al., 1997). An individual patient may have VDB associated with other behavioral disturbances (Swanwick, 1995), and a given individual may demonstrate more than one type of VDB (Draper et al., 2000).

After reporting that VDB often occurred upon waking in the morning in nursing home patients (Cariaga et al., 1988), the same research group looked into the temporal patterns of VDB of 68 nursing home residents with a mean Mini-Mental State Examination (MMSE) score of 9.5 (Burgio et al., 2001). Residents exhibited an average of 15 occurrences of VDB per hour with an average duration per occurrence of 40 seconds. Cluster analysis suggested three distinct temporal patterns of VDB: (1) a relatively constant pattern of low rate VDB, (2) a cyclic pattern of VDB with a peak in the late morning (11 am to noon), and (3) one with a peak at 3 to $4 \mathrm{pm}$.

Other behavioral disturbances, such as physical aggression or sleep disturbance, are likely to be associated with VDB (Ryden, 1988; Draper et al., 2000). However, these associations seem to be guided by complex interplays as physical aggression was lower in those who screamed, but it increased with the rate of screaming (Pomara et al., 2005). 
In summary, VDB comes under many headings and it must be assessed further in terms of its quality (type, intensity, repetitiveness) and its context (etiological and teleological characteristics), as discussed below. However, although this phenomenological approach has face validity, no factor analyses to group interdependent variants of VDB or related etiological or teleological variables have ever been carried out.

\section{Prevalence of VDB}

The prevalence of VDB varies between $10 \%$ and $40 \%$ in nursing homes (Rosin, 1977; Cariaga et al., 1988; Sloane et al., 1998; Cohen-Mansfield et al., 1990; 2003; Whall et al., 1992). However, other studies report higher frequencies (Rosin, 1977), in particular when less disruptive vocal behaviors or their repetitiveness are taken into account. For example, repeated questions and queries: $66.1 \%$ daily, $24.4 \%$ weekly; persistent calling: $42.4 \%$ daily, $39.4 \%$ weekly; verbal aggression: $20.2 \%$ daily, $28.6 \%$ weekly (Hantikainen et al., 1998). Unsurprisingly, frequency estimations depend on how VDB is defined. Thus, breaking down VDB, the frequency of screaming was found in $51 \%$ of VDB, abusive language in $37 \%$, moaning in $33 \%$, repetitive verbalizations in $25 \%$, and other vocalizations in $17 \%$ (Cariaga et al., 1991). Similarly, frequencies varied depending on the presumed etiology of VDB: purposeless and persistent noisemaking in $9 \%$ to $10.4 \%$ of cases, noise-making as a response to the environment in $6.5 \%$ to $9.4 \%$, noise-making that appears directed towards eliciting a response from the environment in $3.9 \%$ to $7 \%$, "chatterbox" noise-making in $1.6 \%$ to $2.8 \%$, noise-making in the context of deafness in $1.2 \%$ to $1.4 \%$, and other noisemaking in $2.5 \%$ to $4.4 \%$ (Ryan et al., 1988). In summary, there is little doubt that the prevalence of VDB is high in nursing home residents. However, due to both the variable nature and repetitiveness of VDB, epidemiological studies are lacking, and the largest study reported is based on a sample of 408 subjects (Cohen-Mansfield et al., 1990).

\section{Factors causing VDB}

Most previous studies have found VDB to be associated with dementia, particularly with severe cognitive impairment and increasing dependency complicated by psychosis, sleep disturbance, depression and other agitated behaviors. Therefore, diagnostic issues are clearly at stake.

Indeed, $59 \%$ of those with VDB had dementia as opposed to $37 \%$ in a nondemented comparison group (Cariaga et al., 1991). Thus, although dementia is more often than not the underlying condition, this is not the general rule. In a study of 28 subjects with VDB, dementia was diagnosed in 20 subjects and with decreasing frequency in those with depression, mental retardation, delirium, psychosis and mania, with multiple diagnoses being allowed (Draper et al., 2000). Although it appears evident that dementia as a syndrome is associated with the occurrence of VDB, it remains unclear whether or not the type 
of dementia predicts the type or frequency of VDB. Differences between different types of dementia have, however, been reported, but there is very little published data on this. However, the duration of the stream of utterances in subjects with Alzheimer's disease was longer than that in individuals with other dementias(Cohen-Mansfield et al., 2003).

Because specific dementia types have some predilection for specific brain regions, indirect evidence for differing VDB prevalence in the various dementias may be gained from anatomo-clinical correlation studies. While the frontal variant of fronto-temporal dementia affects predominantly the orbito-frontal cortex in the early stages of the disease, Alzheimer's disease is characterized by lesions appearing in the medial temporal lobes. However, although socially disruptive behavior is associated with lesions in the anterior frontal and the temporal lobes, as observed in the fronto-temporal dementias (Hall and O'Connor, 2004), few studies have specifically investigated clinico-anatomical correlations referring to VDB. One study on agitation in 427 subjects with dementia came close to this objective and concluded that agitation was a manifestation of frontal lobe dysfunction (Senanarong et al., 2004) where agitation comprised non-compliance with care, refusal to cooperate with the caregiver, obstinacy, resistance, kicking, hitting, being hard to handle, and cursing as a single VDB item. The conclusion was that agitation was correlated with frontally mediated behaviors, including disinhibition, irritability, delusions and aberrant motor activity, a conclusion that may be, however, in part tautological. Damage to orbito-frontal structures resulting in inhibition, and damage to dorso-lateral prefrontal structures leading to impaired decisionmaking may be a cause of VDB (Sloane et al., 1997). Likewise, so-called silent cerebral infarctions of the prefrontal areas and related basal ganglia structures with or without dementia are likely to be associated with disruptive behaviors. This was found in a case series of 12 elderly patients exhibiting confused and disturbed behaviors, some of whom had VDB (verbal aggression, foul language, rambling) associated with other behavioral disturbances (Nagaratnam et al., 2003a). In an apparently different group of 12 patients with VDB and severe vascular or degenerative dementia, the same research group established a link between disruptive behavior and the prefrontal cortex or its connections, but no clear associations between VDB and specific prefrontal and sub-cortical structures emerged (Nagaratnam et al., 2003b). One patient with bilateral thalamic glioma presented frontal-like symptoms and made weird and loud grunting noises (Nagaratnam et al., 2001b).

The dementia stage is likely to play a crucial role. In a study including 88 patients, the MMSE score correlated negatively with VDB and was its most important predictor (Beck et al., 1998). On the Functional Assessment Staging (FAST) the subjects with VDB showed greater impairment (FAST 6e) than the controls (FAST 6b) (Draper et al., 2000). This finding is in keeping with the largest study so far on VDB in which screaming was associated with cognitive impairment and severe impairment in the performance of activities of daily living (Cohen-Mansfield et al., 1990). Patients with VDB were more often bedridden than those without VDB (Draper et al., 2000). However, VDB sometimes occurs in subjects with only mild cognitive impairment (Cariaga et al., 1988; Beck 
et al., 1998; Nagaratnam et al., 2001a). However, differences between studies may be accounted for by methodological issues (Burgio et al., 2001).

Affective disorders and anxiety may also be held responsible for VDB. In a small study of 28 subjects with VDB, six patients had depression, one had mania and the other 20 subjects had dementia (multiple diagnoses possible) (Draper et al., 2000). However, mean scores on the Cornell depression scale were significantly higher in those with VDB while cognitive functioning, as tested by the abbreviated mental test, was not significantly different between the groups. Although the relationship between VDB and depressive symptoms remains unclear, another study found similar results. Comparing 41 residents with VDB and 43 vocally disruptive nursing home residents with a MMSE of at least 10, those with VDB scored significantly higher than the control subjects on three depression scales, even after correction for cognitive impairment, age and gender (Dwyer and Byrne, 2000). VDB may lead to avoidance or retaliation by others and subsequently to feelings of loss and depression, although no studies on temporal links between the appearance of VDB and depression in the demented or non-demented exist (Dwyer and Byrne, 2000). Anxiety may constitute a further cause of VDB (Doyon et al., 1993), and arousal produced by depression-related anxiety may result in VDB (Draper et al., 2000).

VDB can be seen as a way in which a person with impairment in language or communication skills - whether or not they have dementia - can express themselves and their needs. Indeed, people with severe vascular or degenerative dementia and VDB often show markedly reduced speech (Nagaratnam et al., 2003b). Expressive communication skills were significantly more impaired in screamers than in those without VDB (Doyon et al., 1993). In a study of 59 people with dementia, those with altered language skills manifested VDB at a greater frequency than those with preserved language (Matteau et al., 2003). Thus, restrictions in communicative behavior could be a significant determinant of disturbed behavior in some patients though this correlation is not universally found (Nagaratnam et al., 2003b). VDB was reported in non-demented patients with psychosis secondary to Parkinson's disease and mental retardation (Draper et al., 2000), possibly as a consequence of communication impairment, and, more specifically during sleep in those with Parkinson's disease, as a concomitant of REM sleep behavior disorder (Nakamuro et al., 1998). In younger patients, constant screaming was described in a psychotic person as a means of stopping thought interference (Spence, 1999). Generally speaking, and from a functional perspective, all behavior serves a communicative purpose (Clavel, 1999). VDB may therefore reflect an underlying need to communicate discomfort due to pain, thirst, hunger, and inappropriate room temperature which may be undetected or ignored by staff (McMinn and Draper, 2005) or be the response to inappropriate mental or physical stimuli (Draper et al., 2000). Indeed, patients in nursing homes with VDB were prescribed analgesic drugs less often than those without VDB (Cariaga et al., 1991). Furthermore, caregivers' attitudes towards nursing home patients may well be one of the causes of disruptive behaviors since communication may reflect attitudes held towards a patient (Burgener et al., 1992). Thus, clarifying whether or not the staff are causing or reinforcing VDB by the way they interact with the patient is paramount. A higher frequency 
of short corrective interactions with dementia patients was significantly more frequent in those with VDB than in those without (Hallberg et al., 1990) while friendliness may increase calm and peacefulness in the elderly.

Physical comorbidities did not predict disruptive behavior (including VDB) in 88 nursing home residents with severe dementia (Beck et al., 1998). Similarly, physical health was comparable in those with and without VDB, and the overall number of drugs prescribed was the same in both groups except, of course, for the significantly higher rates of psychotropic use in those with VDB, suggesting not only that patients with VDB are given more psychotropics than those without, but also that VDB can at times be drug induced (Draper et al., 2000). However, in cognitively intact residents, a larger number of medical diagnoses was a significant predictor of VDB (Cohen-Mansfield et al., 1999). VDB may be particularly frequent if the patient suffers from hearing loss, visual impairment, or other sensory deprivation (Doyon et al., 1993; Sloane et al., 1997; Vance et al., 2003; McMinn and Draper, 2005), although visual impairment had a protective effect in a mixed group of agitated nursing home residents after controlling for other predictive relationships (Vance et al., 2003). This finding may, in part, overlap in terms of VDB causality with the difficulties that sensory-deprived patients may have in communicating with others.

Both environmental over- and under-stimulation may be responsible for the genesis of VDB, particularly in patients with sensorial impairment as just mentioned (Sloane et al., 1997). However, as well as impairment of the senses, social deprivation may be a risk factor for VDB as much as over-stimulation, e.g. through numerous short interaction episodes (McMinn and Draper, 2005). Screaming was more frequent when residents were left alone in their rooms during the evening (Cohen-Mansfield et al., 1990).

Whether or not premorbid characteristics such as ethnic and gender differences or premorbid personality determine VDB is by and large unknown. However, in two studies it has been shown that African-American and Latino communitydwelling patients with moderate to severe dementia were more constantly talkative (other VDB was not assessed) than their white counterparts (Sink et al., 2004; Beach et al., 2005). Although the reasons for this difference are unclear, white patients with dementia-related behaviors may be more likely to be institutionalized. Although the relationship between gender and VDB has not been evaluated systematically, VDB may be more frequent in both cognitively impaired and non-impaired men than in women (Beck et al., 1998; CohenMansfield et al., 1999) although women showed higher agitation - particularly VDB - than men in other studies (Vance et al., 2003). The influence of personality traits on behavioral and psychological symptoms in dementia is an almost completely ignored field of research. However, a few rare studies find associations between premorbid personality characteristics and behavioral changes occurring during dementia (Meins et al., 1998; Gould and Hyer, 2004), but only one study explores the issue of VBD and associated premorbid personality characteristics. Using the Eysenck Personality Inventory filled in by close relatives, this small study finds that 21 subjects with severe dementia and VBD were more introverted and rigid with a tendency to control emotions before the onset of dementia than 19 matched patients without VBD (Holst et al., 1997). Although not all studies 
find a relationship between a premorbid personality and subsequent behavioral and psychological symptoms in dementia (Low et al., 2002), it seems essential to try to understand how people with dementia interpret and cope with situations from the vantage point of their life perspectives.

Different types of $V D B$ may be associated with different causal factors. Thus, "screamers" producing nonverbal noises had more hearing impairments, more severe cognitive impairments and greater dependency in their activities of daily living than the "talkers" whose predominant expressions were words (Sloane et al., 1999). Whether or not the three distinct temporal patterns of VDB reported above (i.e. cluster $1=$ a relatively constant pattern of low rate VDB; cluster $2=$ a cyclic pattern of VDB with a peak at 11 am to 12 noon; and cluster $3=$ a cyclic pattern of VDB with a peak at 3 to $4 \mathrm{pm}$ ) are related to physiological factors, environmental events or both is unknown. However, cluster 3 is reminiscent of sundowning (Burgio et al., 1994) while cluster 2 describes the increase in VDB around lunchtime, suggesting that hunger or the increase of ward activity at mealtime might increase VDB (Burgio et al., 2001).

There are no definite guidelines on how to assess $V D B$, but empirically useful ways of proceeding have been described (Cohen-Mansfield and Werner, 1997a; Sloane et al., 1997; Barton et al., 2005). In short, the multiple etiologies of VDB call for a thorough and multidisciplinary assessment that includes the careful description of VDB and the attempt to understand the message it is likely to convey. Triggers that bring on or worsen VDB requiring must be sought through careful observation, possibly over several days. A medical examination is mandatory and targeted laboratory testing can be helpful to deal with new or reactivated physical or psychiatric disorders. If not already done, assessment of the patient's premorbid history, both medical and personal, is indispensable to endeavor to make sense of a subject's VDB. More formalized assessments, at least as to the types of VDB, have been suggested. One such typology of VDB takes into account the quality, the purpose, the response to the environment as well as the quantity of the behavior and was formalized as the "typology of vocalizations and screaming behavior mapping instrument" (Cohen-Mansfield and Werner, 1994; 1997a). This comprehensive procedure comes close to the description given in Table 1 and as such has good face validity. Yet another instrument is the "survey of disruptive vocal behavior" (Burgio et al., 2001).

In summary, a plethora of factors may be instrumental in causing VDB, which suggests that VDB is an equifinal and end-of-route behavior. However, this does not mean that better characterization of causal factors should not be sought for each individual patient; on the contrary, the factors discussed above are hardly defined in terms of them being causative, precipitating or protective. VDB must be analyzed according to a considerable number of potential etiopathogenic or causative factors before deciding on the course of treatment. Indeed, this assessment will form the basis for a reasonable treatment plan that usually comprises a combination of various components (Sloane et al., 1997). Treatment, however, is the crucial issue when we are confronted with patients with VDB because of the consequences for both the patients themselves and those around them. 


\section{Treatment}

\section{Consequences of VDB}

VDB is associated with increased mortality though possibly secondary to older age and more advanced dementia (Cohen-Mansfield et al., 1999; Allen et al., 2005). More importantly, as VDB is among the most disruptive of behaviors, it may have various effects on others such as reactive verbal or otherwise aggressive retaliation by other residents, avoidance of contact with the screamer by staff, or chemical or physical constraints (Sloane et al., 1997; Dwyer and Byrne, 2000). Nursing staff expressed significantly more frustration, anxiety and anger toward subjects with VDB and sought to distance themselves from them (Draper et al., 2000). In extreme situations, these patients may be exposed to maltreatment (Jeandel, 2004), and to potentially harmful behavior by an informal caregiver depending on the patient's mental and physical frailty (Beach et al., 2005). Nevertheless, the majority of nursing home staff either showed no reaction to VBD or reacted in a pleasant manner; indeed, formal caregivers believed that such disruptive behavior had more negative consequences for the other nursing home residents than on themselves (Cohen-Mansfield et al., 1990). Furthermore, caregivers working fewer hours reported less difficulty in enduring persistent calling than those with a higher workload (Hantikainen et al., 1998). However, negative consequences on those around a patient with VDB are among the more important reasons for referral for treatment (Draper et al., 2000).

\section{Treatment proper}

Numerous biological, behavioral and environmental treatments or managements have been used by caregivers. Physical or chemical treatments are reported to be often used as initial interventions (Hantikainen et al., 1998), although the former has been shown to increase disruptive behaviors in many instances (Werner et al., 1989). However, whatever treatment is applied, the decision must be preceded by a thorough analysis of causative or aggravating factors of VDB, as stated above, in order to put forward a promising working hypothesis.

\section{BIOLOGICAL INTERVENTIONS}

Medication Medication should not be given indiscriminately to patients with VDB as a convenient treatment to achieve compliance. Medications can be of limited effectiveness and may carry a significant risk of adverse effects in the management of VDB (Sloane et al., 1997). However, the idea of using medications cannot simply be dismissed. If VDB has been thoroughly analyzed and is considered to be a manifestation of pain, medications are to be given (Drinka and Bobbe, 1990). Pain is often underdiagnosed and undertreated in patients with dementia (Morrison and Siu, 2000), and this may be true for those with VDB. Thus, the treatment of pain using analgesics, sedatives and tranquilizers was perceived by nurses to be effective in approximately $88 \%$ of all cases, although little research has been carried out in those suffering from dementia (Rogers et al., 1987; McMinn and Draper, 2005). Thorough physical examination and the subsequent treatment of the underlying medical condition 
Table 2. Studies of biological interventions that show some effectiveness on VDB

\begin{tabular}{|c|c|c|c|}
\hline A UTHORS & $\begin{array}{l}\text { NUMBER } \\
\text { OF CASES }\end{array}$ & INTERVENTION & STUDY TYPE \\
\hline Friedman et al., 1992 & 11 & Doxepin & $\begin{array}{l}\text { Retrospective } \\
\text { case audit }\end{array}$ \\
\hline Greenwald et al., 1986 & 1 & Trazodone/L-tryptophan & Case report \\
\hline Kim et al., 2000 & 2 & Citalopram & Case series \\
\hline Kopala and Honer, 1997 & 2 & Risperidone & Case series \\
\hline Pasion and Kirby 1993 & 1 & Trazodone & Case report \\
\hline Pollock et al., 1997 & 14 & Citalopram & Case series \\
\hline Ramadan et al., 2000 & 15 & Paroxetine & Case series \\
\hline Rogers et al., 1987 & 19 & 15 different interventions & Case series \\
\hline Carlyle et al., 1991 & 3 & ECT & Case series \\
\hline Roccaforte et al., 2000 & 1 & ECT & Single case \\
\hline
\end{tabular}

clearly relieved both the patients' suffering and VDB (Cohen-Mansfield and Werner, 1997b). However, the general effectiveness of psychotropics was estimated to be as low as $44 \%$ (Burgio et al., 1988), though most published studies are little more than case reports, as shown in Table 2.

Sudden unexplained vocalizations or crying spells may respond to antidepressants (Sloane et al., 1997). Antidepressants used are citalopram, paroxetine or a combination of trazodone and L-tryptophan, although their effectiveness may be delayed by up to three weeks (Greenwald et al., 1986; Pasion and Kirby, 1993; Verma et al., 1998; Kim et al., 2000; Ramadan et al., 2000). The association between low serotonin levels and increased impulsivity provides a pharmacological rationale for the use of medications with serotoninergic properties as those just mentioned (Sloane et al., 1997). However, in some cases serotoninergic antidepressants may not be effective at all (Nagaratnam et al., 2003b).

Neuroleptics have also been found useful. The atypical antipsychotics risperidone and olanzapine were shown to be somewhat superior to promazine for the treatment of behavioral and psychological symptoms of dementia, but no specific data on VDB were given (Gareri et al., 2004). According to a retrospective chart review, risperidone was more effective than either haloperidol or olanzapine on behavioral and psychiatric symptoms including VDB, at least in people with dementia, in a mixed group of 202 patients of whom 29 had VDB (Frenchman, 2000). Similarly, low doses of risperidone decreased VDB (Goldberg and Goldberg, 1996). Antipsychotics with the fewest anticholinergic side effects are indicated for elderly patients with VBD and psychotic symptoms (Sloane et al., 1997). While some patients with severe dementia and VDB are responders, others may not respond at all to drugs such as haloperidol or risperidone (Nagaratnam et al., 2003b).

Other medications used to treat behavioral and psychological symptoms include benzodiazepines, thymoregulators, psychostimulants, and possibly acetylcholinesterase inhibitors, but no data specific appertaining to VDB are available (Sloane et al., 1997; Verma et al., 1998; Barton et al., 2005). 
Despite the likely efficacy of some of these drugs in treating VDB, the referral of patients with VDB who are already receiving psychotropic medication is testimony to the relative ineffectiveness of this approach when used alone (Draper et al., 2000). Overall, the current effect of biological treatments for VDB remains open to question and the use of medications is based on research mainly relating to behavioral and psychological symptoms other than VDB. It cannot be safely assumed that the effect of drugs on VDB will be similar to that on other behavioral symptoms.

Electro-convulsive therapy (ECT) ECT was used very efficiently according to anecdotal reports of patients with very disturbing VDB who did not respond to a series of other treatments. Thus, after five ECT treatments, VDB had completely ceased and had not reappeared during divalproex sodium maintenance treatment one year after ECT (Roccaforte et al., 2000). Three elderly patients with medication-resistant VDB, one of whom had major depression and two who had a substantial degree of cognitive impairment, exhibited rapid resolution of screaming early in their course of ECT (Carlyle et al., 1991).

\section{PSYCHOSOCIAL INTERVENTIONS}

A key element in treating VDB is the prior assessment of environmental factors that may contribute to VDB or cause it. Reframing VBD positively as a communication effort by a mentally impaired subject is a first step toward effective management (Clavel, 1999). A number of management strategies for disruptive behaviors in general have been described (Whall et al., 1992) and a wide range of empirically based and expert-derived attitudes toward managing specific causes of VDB have been suggested (Sloane et al., 1997; Hantikainen et al., 1998). They include direct interventions focusing on the patient with VDB, varying from savoir-être approaches (social competencies) and specific care attitudes or environmental interventions to reinforcement strategies, and indirect interventions via formal caregivers. Savoir-être approaches and specific care attitudes or environmental interventions comprise talking to and counseling patients, showing attention, remaining calm, approaching the patient in a nonhurried and non-demanding manner, touching, bathing and diversion (i.e. engaging patients in activities such as exercise, chores, music therapy, sensory stimulation, hypostimulation). Interventions that have been tested specifically to decrease VDB are summarized in Table 3.

Direct interventions focusing on the patient's needs As mentioned above, these may consist of (1) savoir-être and common sense approaches, (2) specific care attitudes or environmental interventions, and (3) reinforcement strategies.

(1) Savoir-être and commonsense approaches. VDB occurs frequently among cognitively impaired residents who mimic actions or emotions of caregivers or respond mirror-like to them, yet these patients usually remain sensitive to friendly and soothing contact. Thus, caregivers should adhere to some general management principles or care attitudes including remaining calm 


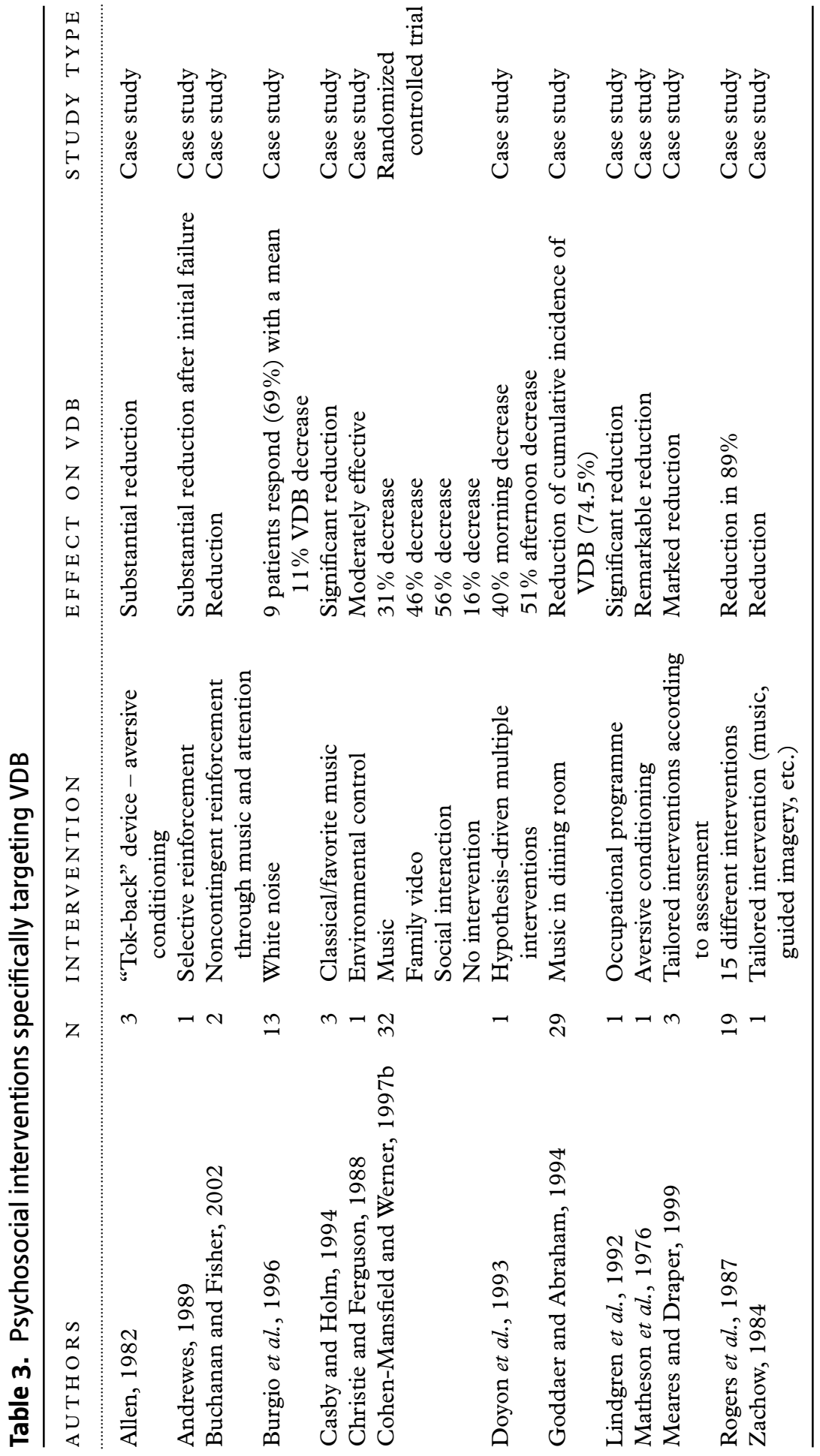


and approaching the resident in a friendly, non-hurried, and non-demanding manner. Thus, positive statements by nursing assistants directed at patients with dementia in nursing homes were associated with a reduced likelihood of agitation onset, with VDB being the most prevalent form of agitation (Roth et al., 2002).

(2) Specific care attitudes and environmental interventions. Pacing, defined here as matching the caregiver's verbal or non-verbal behavior to the patient's behavior, has been suggested (White et al., 1996). Creating a familiar homelike environment wherever possible has been suggested as a way of reducing the negative influence of environmental factors associated with VDB, although no specific study has been conducted to test this advice (White et al., 1996). Music therapy, guided imagery, fantasy and sensory stimulation helped reduce the calling behavior of a 67-year-old nursing home resident (Zachow, 1984). Additionally, after eight weeks of therapy, other benefits were also observed as the woman was quieter, slept better, and was more alert. Similarly, music was a viable method of reducing VDB in three patients with dementia (Casby and Holm, 1994) and in 29 cognitively impaired nursing home residents (Goddaer and Abraham, 1994). Spa bathing in the evening may have positive effects on behavioral symptoms including VDB (Deguchi et al., 1999). However, some of the above-mentioned care attitudes are little more than part of what should be every carer's savoir-être and as such they have empirical validity and need no scientific proof. These care attitudes can nonetheless be viewed as therapeutic measures as VDB often serves a communicative purpose. Savoir-être effectively embraces VDB as an attempt to communicate (Meares and Draper, 1999). Interestingly, the quality of relationships with others proves consistently significant and related to both short, one-year and overall survival in nursing home residents (Cohen-Mansfield et al., 1999).

Not only have environmental interventions hardly been investigated, except for the case studies mentioned above, but studies investigating the differential efficiency of interventions on VDB also remain comparatively rare. One such study of 32 nursing home residents with moderate dementia found VDB to be decreased by $56 \%$ during social interaction, by $46 \%$ while watching a video, and by $31 \%$ during music chosen by the patients compared with $16 \%$ in the non-intervention setting (Cohen-Mansfield and Werner, 1997b). Repositioning was identified as effective in $89 \%$ of the patients while touching and talking to the patients were considered effective in less than half of them (Rogers et al., 1987). Showing attention was effective in $50 \%$ of cases, reading to the patient in $29 \%$, and touching in $32 \%$ (Burgio et al., 1988).

(3) Reinforcement strategies. VDB can be reinforced through family or staff members, strangers and visitors if they adjust to those with VDB. Thus, ignoring negative behavior and rewarding (and thereby reinforcing) positive behavior is a theoretical treatment option. Indeed, many brain-damaged patients are still capable of procedural learning as their subcortical structures may be unimpaired. However, only anecdotal reports on this treatment option are available for a handful of patients with VDB. It was used successfully in a patient who had been treated for anoxic encephalopathy (Andrewes, 1989) and is also recommended in patients with dementia (White et al., 1996). Reward items include food, 
tobacco or snuff, contact with animals, children, or family and staff members (Sloane et al., 1997). Reinforcement of non-screaming behavior may not be sufficient, and punishment can be an alternative or add-on method (Matheson et al., 1976). While only a few case reports indicate positive outcomes (Matheson et al., 1976), this treatment approach is difficult to implement and also gives rise to a number of ethical questions. An audio-amplification device helped reduce VDB in three mentally retarded subjects (Allen, 1982) by transmitting the patients' vocalizations to their own auditory systems. While reinforcement by rewarding patients for silence or appropriate requests can be efficient (Swanwick, 1995), it must be emphasized that this complex treatment approach is often hampered by its inconsistent implementation by nursing staff.

Indirect interventions focusing on the caregivers' needs An important role of specialist services is to provide education and emotional support to nursing staff. Assisting caregivers in coming to terms with their own emotional reactions to difficult patients through effective leadership and regular supervision is paramount (White et al., 1996). Creative role playing and teaching may be useful (White et al., 1996; McMinn and Draper, 2005), but reassuring staff that they are doing a good job is often required (Draper et al., 2000). Remembering or reminding others that VDB is not to be taken personally even if it appears to be directed at them is crucial (Sloane et al., 1997). Most importantly, training and education of professional caregivers can ultimately have a positive impact on the patients themselves although this has rarely been assessed in relation to VDB (Proctor et al., 1999). However, in one study, a training program significantly improved the quality of verbal instructions given to patients by nursing assistants (Roth et al., 2002). It is noteworthy that no published research was found on interventions by informal caregivers of patients with VDB, although minor or moderate VDB often occurs at home (Koss et al., 1997); this lack of published research might suggest that the environment in which a patient lives is a crucial determinant or catalyst for VDB.

In summary, little is known about the efficacy of specific treatments for patients with VDB. At this stage, treating VDB generally implies the use of multiple interventions tailored to the individual's needs after multidisciplinary evaluations, and useful algorithms with face validity, but no research confirmation has been suggested (Barton et al., 2005).

\section{Conclusions}

A straightforward definition of VDB is hampered by the multifaceted aspects of this behavior. Defining its quality both in terms of type and physical characteristics is not sufficient as ethiopathogenic aspects, its temporality, and the consequences VDB ought to be part of the definition. Defining VDB according to a matrix comprising the above dimensions may be more appropriate than defining it as a single behavior. This matrix approach comes close to how clinicians may try to analyze VDB in their patients, but in the research environment this proves almost impossible - it is very difficult to operate with 
a variable itself composed of a variety of dimensions. This approach needs high numbers of patients showing this complex and heterogeneous behavior; large numbers would then allow statistical cluster and factor analyses of the pooled data and eventually yield subtypes of VDB that might be better defined in terms of type and etiopathogeny. However, an adequate number of patients with VDB is precisely what is lacking in the research studies we have examined so far. As a consequence, our approach to patients with VDB mostly follows clinical common sense, such as the savoir-être approach, while other approaches still await proper study. Even prevalence data are hardly trustworthy due to heterogeneous definitions, the almost exclusive use of institutional settings, and the absence of sufficiently large study populations. What is certain, however, is that $\mathrm{VDB}$ is a common enough problem in nursing homes to warrant more attention. Etiopathogenic knowledge of VDB remains fragmentary, apparently due to the high number of factors involved - biological, psychological and environmental - and their complex interplay. These factors include not only those anchored in the present, but also premorbid personality characteristics and social interactiveness, an almost entirely pristine field of study. Despite the multitude of factors potentially involved in causing or precipitating VDB, this behavior, or some forms of it, is likely to be an equifinal behavior, i.e. one whose phenomenology is at least in part independent of its etiology. Nonetheless, understanding the complex and multiple origins of VDB is central to the accurate treatment of this condition. Most importantly, our review shows that hardly any studies exist on treatments for VDB, and the few case studies that we have reported here suggest that although many approaches may have at least some efficacy, hardly any treatment - be it biological, psychological or environmental - can be regarded as sufficient as a single intervention. Most often a range of different interventions will be required to stop or at least reduce a patient's VDB and suffering. As emphasized above, treating VDB in most situations implies the use of multiple interventions tailored to the individual's needs based on multidisciplinary evaluations, and of useful algorithms requiring research confirmation. Comparative studies of interventional studies may be useful, but discrepant results are likely to occur, in part because the studies may not target individually relevant attitudes to VDB. Different types of research methodology are therefore appropriate, and hypothesis-driven and etiologically oriented studies using multiple but clearly documented interventions might be of interest. This is similar to the matrix approach to the phenomenology of VDB advocated above.

Since Teri and colleagues concluded in 1992 that there were hardly more than a few anecdotal case reports on the treatment of VDB (Teri et al., 1992), the situation has changed little. We may have learnt more about the clinical and etiological aspects of VDB, but the literature still abounds with contradictions and little new information has been added on effective treatments.

\section{Conflict of interest}

None. 


\section{Description of authors' roles}

Armin von Gunten designed the review, analyzed the literature and wrote the paper. Abdel-Messieh Alnawaqil helped analyze the literature and contributed to the writing of the paper. Christoph Abderhalden helped design the review and analyze the literature. Ian Needham contributed to the writing of the paper. Brigitte Schüpbach helped design the review and analyse the literature and contributed to the writing of the paper.

\section{References}

Allen, L. D. (1982). Reduction of disruptively loud voice volume using a "tok-back" device. Applied Research in Mental Retardation, 3, 67-80.

Allen, R. S., Burgio, L. D., Fischer, S. E., Hardin, J. M. and Shuster, J. L. (2005). Behavioral characteristics of agitated nursing home residents with dementia at the end of life. The Gerontologist, 45, 661-666.

Alzheimer, A. (1907). Über eine eigenartige Erkrankung der Hirnrinde. Allgemeine Zeitschrift für Psychiatrie und Psychisch-Gerichtliche Medizin, 64, 146-148.

Andrewes, D. (1989). Management of disruptive behaviour in the brain-damaged patient using selective reinforcement. Fournal of Behavior Therapy and Experimental Psychiatry, 20, 261-264.

Barton, S., Findlay, D. and Blake, R. A. (2005). The management of inappropriate vocalisation in dementia: a hierarchical approach. International fournal of Geriatric Psychiatry, 20, 1180-1186.

Beach, S. R., Schulz, R., Williamson, G. M., Miller, L. S., Weiner, M. F. and Lance, C. E. (2005). Risk factors for potentially harmful informal caregiver behavior. Fournal of the American Geriatrics Society, 53, 255-261.

Beck, C. et al. (1998). Correlates of disruptive behavior in severely cognitively impaired nursing home residents. The Gerontologist, 2, 189-198.

Buchanan, J. A. and Fisher, J. E. (2002). Functional assessment and noncontingent reinforcement in the treatment of disruptive vocalization in elderly dementia patients. Fournal of Applied Behavior Analysis, 35, 99-103.

Burgener, S. C., Jirovec, M., Murrel, L. and Barton, D. (1992). Caregiver and environmental variables related to difficult behaviors in institutionalized, demented elderly persons. Fournal of Gerontology, 47, 242-249.

Burgio, L. D., Flynn, W. and Martin, D. (1988). Disruptive vocalizations in institutionalized geriatric patients. The Gerontologist, 28, 369-371.

Burgio, L. D. et al. (1994). Studying disruptive vocalization and contextual factors in the nursing home using computer-assisted real-time observation. Fournal of Gerontology, 49, 230-239.

Burgio, L., Scilley, K., Hardin, M., Hsu, C. and Yancey, J. (1996). Environmental "white noise": an intervention for verbally agitated nursing home residents. Fournal of Gerontology: Psychological Sciences and Social Sciences, 51B, P364-P373.

Burgio, L. D., Scilley, K., Hardin, J. M. and Hsu, C. (2001). Temporal patterns of disruptive vocalization in elderly nursing home residents. International Fournal of Geriatric Psychiatry, 16, 378-386.

Cariaga, J., Burgio, L. D., Flynn, W. and Martin, D. (1988). Disruptive vocalizations in institutionalized geriatric patients. The Gerontologist, 28, 264A. 
Cariaga, J., Burgio, L., Flynn, W. and Martin, D. (1991). A controlled study of disruptive vocalizations among geriatric residents in nursing homes. Fournal of the American Geriatrics Society, 39, 501-507.

Carlyle, W., Killick, L. and Ancill, R. (1991). ECT: an effective treatment in the screaming demented patient. Fournal of the American Geriatrics Society, 39, 637.

Casby, J. A. and Holm, M. B. (1994). The effect of music on repetitive disruptive vocalizations of persons with dementia. American fournal of Occupational Therapy, 883-889.

Christie, M. and Ferguson, G. (1988). Can't anyone stop that screaming? The Canadian Nurse, 84, 30-32.

Clavel, D. S. (1999). Vocalizations among cognitively impaired elders. What is your patient trying to tell you? Geriatric Nursing, 20, 90-93.

Cohen-Mansfield, J. and Werner, P. (1994). Verbally disruptive behaviors in elderly persons: a review. Facts and research in gerontology. In B. J. Vellas, J. L. Albaredo and P. J. Garry (eds.), Dementia and Cognitive Impairment (pp. 73-89), Paris: Serdi.

Cohen-Mansfield, J. and Werner, P. (1997a). Typology in disruptive vocalizations in older persons suffering from dementia. International fournal of Geriatric Psychiatry, 12, 1079-1091.

Cohen-Mansfield, J. and Werner, P. (1997b). Management of verbally disruptive behaviors in nursing home residents. Fournal of Gerontology: Biological Sciences and Medical Sciences, 6A, M369-377.

Cohen-Mansfield, J., Werner, P. and Marx, M. S. (1990). Screaming in nursing home residents. Fournal of the American Geriatrics Society, 38, 785-792.

Cohen-Mansfield, J., Marx, M. S., Lipson, S. and Werner, P. (1999). Predictors of mortality in nursing home residents. Fournal of Clinical Epidemiology, 52, 273-280.

Cohen-Mansfield, J., Werner, P., Hammerschmidt, K. and Newman, J. D. (2003). Acoustic properties of vocally disruptive behaviour in the nursing home. Gerontology, 49, 161-167.

Deguchi, A. et al. (1999). Improving symptoms of senile dementia by night-time spa bathing. Archives of Gerontology and Geriatrics, 29, 267-273.

Doyon, J., Lazure, H. and Lévesque, L. (1993). Les cris répétés. The Canadian Nurse, 89, $42-44$.

Draper, B. et al. (2000). Case-controlled study of nursing home residents referred for treatment of vocally disruptive behavior. International Psychogeriatrics, 12, 333-344.

Drinka, P. J. and Bobbe, M. (1990). Screaming in the nursing home. Fournal of the American Geriatrics Society, 38, 1380.

Dwyer, M. and Byrne, G. J. (2000). Disruptive vocalization and depression in older nursing home residents. International Psychogeriatrics, 12, 463-471.

Frenchman, I. B. (2000). Risperdone, haloperidol, and olanzapine for the treatment of behavioral disturbances in nursing home patients: a retrospective analysis. Current Therapeutic Research, Clinical and Experimental, 61, 742-750.

Friedman, R., Gryfe, C. I., Tal, D. T. and Freedman, M. (1992). The noisy elderly patient: prevalence, assessment, and response to the antidepressant doxepin. Fournal of Geriatric Psychiatry and Neurology, 5, 187-191.

Gareri, P. et al. (2004). Comparison of the efficacy of new and conventional antipsychotic drugs in the treatment of behavioral and psychological symptoms of dementia (BPSD). Archives of Gerontology and Geriatrics, Suppl. 9, 207-215.

Goddaer, J. and Abraham, I. (1994). Effects of relaxing music on agitation during meals among nursing home residents with severe cognitive impairment. Archives of Psychiatric Nursing, 8, 150-158.

Goldberg, R. J. and Goldberg, J. (1996). Antipsychotics for dementia-related behavioural disturbances in elderly institutionalized patients. Clinical Geriatrics, 4, 58-68. 
Gould, S. L. and Hyer, L. A. (2004). Dementia and behavioral disturbance: does premorbid personality really matter? Psychological Reports, 95, 1072-1078.

Greenwald, B. S., Marin, D. B. and Silverman, S. M. (1986). Serotoninergic treatment of screaming and banging in dementia. The Lancet, 2, 1464-1465.

Hall, K. A. and O'Connor, D. W. (2004). Correlates of aggressive behavior in dementia. International Psychogeriatrics, 16, 141-158.

Hallberg, I. R., Luker, K., Norberg, A., Johnsson, K. and Eriksson, S. (1990). Staff interaction with vocally disruptive demented patients compared with demented controls. Aging, 2, 163-171.

Hantikainen, V., Isola, A. and Helenius, H. (1998). Störendes Verhalten älterer HeimbewohnerInnen und die Anwendung von Pflegemethoden: eine deskriptive Studie über Schweizer Pflegeheime. Pflege, 11, 78-88.

Holst, G., Hallberg, I. R. and Gustafson, L. (1997). The relationship of vocally disruptive behavior and previous personality in severely demented institutionalized patients. Archives of Psychiatric Nursing, 6, 147-154.

Hussian, R. A. and Hill, S. D. (1980). Sterotyped behaviour in elderly patients with chronic organic mental disorder. Fournal of Gerontology, 35, 689-691.

Jeandel, C. (2004). Comment gérer la déambulation et les cris du patient atteint de démence. Soins, 685, 44-45.

Kim, K. Y., Bader, G. M. and Jones, E. (2000). Citalopram for verbal agitation in patients with dementia. Fournal of Geriatric Psychiatry and Neurology, 13, 53-55.

Kopala, L. C. and Honer, W. G. (1997). The use of risperidone in severely demented patients with persistent vocalizations. International fournal of Geriatric Psychiatry, 12, 73-77.

Koss, E. et al. (1997). Assessing patterns of agitation in Alzheimer's disease patients with the Cohen-Mansfield Agitation Inventory. Alzheimer Disease and Associated Disorders, 11 (Suppl. 2), S45-S50.

Lindgren, C., Hallberg, I. R. and Norberg, A. (1992). Diagnostic reasoning in the care of a vocally disruptive severely demented patient: a case report. Scandinavian fournal of Caring Sciences, 6, 97-103.

Low, L. F., Brodaty, H. and Draper, B. (2002). A study of premorbid personality and behavioural and psychological symptoms of dementia in nursing home residents. International fournal of Geriatric Psychiatry, 17, 779-783.

Matheson, W. E., Mian, M., MacPherson, F. and Anthony, J. (1976). Control of screaming behavior using aversive conditioning and time-out. Fournal of Psychiatric Nursing and Mental Health Services, 14, 27-28.

Matteau, E., Landreville, P., Laplante, L. and Laplante, C. (2003). Disruptive vocalizations: a means to communicate in dementia? American fournal of Alzheimer's Disease and Other Dementias, 18, 147-153.

McMinn, B. and Draper, B. (2005). Vocally disruptive behaviour in dementia: development of an evidence based practice guideline. Aging and Mental Health, 9, 16-24.

Meares, S. and Draper, B. (1999). Treatment of vocally disruptive bahaviour of multifactorial aetiology. International fournal of Geriatric Psychiatry, 14, 285-290.

Meins, W., Frey, A. and Thiesemann, R. (1998). Premorbid personality traits in Alzheimer's disease: do they predispose to noncognitive behavioral symptoms? International Psychogeriatrics, 10, 369-378.

Morrison, R. S. and Siu, A. L. (2000). A comparison of pain and its treatment in advanced dementia and cognitively intact patients with hip fracture. Fournal of Pain and Symptom Management, 19, 240-248.

Nagaratnam, N., Lim, W. and Hutyn, S. (2001a). Some problematic behaviors in Alzheimer's dementia. Archives of Gerontology and Geriatrics, 32, 57-65. 
Nagaratnam, N., Ting, A. and Jolley, D. (2001b). Thalamic tumour presenting as frontal lobe dysfunction. International fournal of Clinical Practice, 55, 492-493.

Nagaratnam, N., Bou-Haidar, P. and Leung, H. (2003a). Confused and disturbed behavior in the elderly following silent frontal lobe infarction. American fournal of Alzheimer's Disease and Other Dementias, 18, 333-339.

Nagaratnam, N., Patel, I. and Whelan, C. (2003b). Screaming, shrieking and muttering: the noise-makers amongst dementia patients. Archives of Gerontology and Geriatrics, 36, $247-258$.

Nakamuro, T., Futamura, N., Murata, K., Suzumura, A. and Takayanagi, T. (1998). Screaming during sleep in patients with Parkinson disease. Rinsho Shinkeigaku, 38, 457-460 (abstract only).

Pasion, R. C. and Kirby, S. G. (1993). Trazodone for screaming. The Lancet, 341, 970.

Pollock, B. G. et al. (1997). An open pilot study of citalopram for behavioral disturbances of dementia. Plasma levels and real-time observations. American fournal of Geriatric Psychiatry, 5, 70-78.

Pomara, N., Volavka, J., Czobor, P., Hernando, R. and Sidtis, J. J. (2005). Screaming and physical aggression in nursing homes. American fournal of Geriatric Psychiatry, 13, 539-540.

Proctor, R. et al. (1999). Behavioural management in nursing and residential homes: a randomised controlled trial. The Lancet, 354, 26-29.

Ramadan, F. H., Naughton, B. J. and Bassanelli, A. G. (2000). Treatment of verbal agitation with a selective serotonin reuptake inhibitor. Fournal of Geriatric Psychiatry and Neurology, 13, 56-59.

Roccaforte, W. H., Wengel, S. P. and Burke, W. J. (2000). ECT for screaming in dementia. American fournal of Geriatric Psychiatry, 8, 177.

Rogers, J., Haviland, S. and O'Brien, J. (1987). Management of disruptive vocal behaviors in a nursing home population. The Gerontologist, 27, 33A-34A.

Rosin, A. J. (1977). The physical and behavioral complex of dementia. Gerontology, 23, 37-46.

Roth, D. L., Stevens, A. B., Burgio, L. D. and Burgio, K. L. (2002). Timed-event sequential analysis of agitation in nursing home residents during personal care interactions with nursing assistants. Fournal of Gerontology: Psychological Sciences, 578, p461-p468.

Ryan, D. P., Tainsh, S. M., Kolodny, V., Lendrum, B. L. and Fisher, R. H. (1988). Noise-making amongst the elderly in long-term care. The Gerontologist, 28, 369-371.

Ryden, M. B. (1988). Aggressive behavior in persons with dementia who live in the community. Alzheimer Disease and Associated Disorders, 2, 342-355.

Senanarong, V. et al. (2004). Agitation in Alzheimer's disease is a manifestation of frontal lobe dysfunction. Dementia and Geriatric Cognitive Disorders, 17, 14-20.

Sink, K. M., Covinsky, K. E., Newcomer, R. and Yaffe, K. (2004). Ethnic differences in the prevalence and pattern of dementia-related behaviors. fournal of the American Geriatrics Society, 52, 1277-1283.

Sloane, P. D. et al. (1997). Management of the patient with disruptive vocalization. The Gerontologist, 37, 675-682.

Sloane, P. D., Mitchell, C. M., Preisser, J. S., Phillips, C., Commander, C. and Burker, E. (1998). Environmental correlates of resident agitation in Alzheimer's disease special care units. Fournal of the American Geriatrics Society, 46, 862-869.

Sloane, P. D., Davidson, S., Knight, N., Tangen, C. and Mitchell, C. M. (1999). Severe disruptive vocalizers. Fournal of the American Geriatrics Society, 47, 439-445.

Spence, S. A. (1999). A memorable patient: the screaming man. BMF, 319, 489.

Swanwick, G. R. (1995). Nonpharmacological treatment of behavioral symptoms. In B. A. Lawlor (ed.), Behavioral Complications in Alzheimer's Disease (pp. 183-207), Washington DC: American Psychiatric Press. 
Teri, L. et al. (1992). Management of behavior disturbance in Alzheimer disease: current knowledge and future directions. Alzheimer Disease and Associated Disorders, 6, 77-88.

Vance, D. E., Burgio, L. D., Roth, D. L., Stevens, A. B., Fairchild, J. K. and Yurick, A. (2003). Predictors of agitation in nursing home residents. Fournal of Gerontology: Psychological Sciences, 58B, P129-P137.

Verma, S. D., Davidoff, D. A. and Kambhampati, K. K. (1998). Management of the agitated elderly patient in the nursing home: the role of the atypical antipsychotics. Fournal of Clinical Psychiatry, 59, 50-55.

Werner, P., Cohen-Mansfield, J., Braun, J. and Marx, M. S. (1989). Physical restraints and agitation in nursing home residents. Fournal of the American Geriatrics Society, 37, 1122-1126.

Whall, A. L., Gillis, G. L., Yankou, D., Booth, D. E. and Beel-Bates, C. A. (1992).

Disruptive behavior in elderly nursing home residents: a survey of nursing staff. fournal of Gerontological Nursing, 13-17.

White, M. K., Kaas, M. J. and Richie, M. F. (1996). Vocally disruptive behavior. Fournal of Gerontological Nursing, 22, 23-29.

Zachow, K. M. (1984). Helen, can you hear me? Fournal of Gerontological Nursing, 10, 18-22. 